\title{
ВКР-генерация субпикосекундных оптических импульсов в области 1.3 мкм
}

\author{
$\underline{\text { В.Д. Ефремов }}^{1,2}$, Д.С. Харенко ${ }^{1,2, *}$, С.А. Бабин ${ }^{1,2}$ \\ ${ }^{1}$ Институт автоматики и электрометрии СО РАН \\ ${ }^{2}$ Новосибирский государственный университет \\ *E-mail: kharenko@iae.nsk.su
}

DOI:10.31868/RFL2018.80-81

В настоящее время для биомедицинских применений, в первую очередь для различных видов нелинейной микроскопии, востребованы простые и надежные источники субпикосекундных импульсов с высокой пиковой мощностью и длиной волны генерации вблизи 1.3 мкм. Выбор этой длины волны обусловлен тем, что в указанном диапазоне поглощение ОН-групп минимально (первое окно прозрачности) и максимальна прозрачность биологических тканей. Высокая пиковая мощность обеспечивается при генерации сильночирпованных диссипативных солитонов (СЧДС). В то время как генерация излучения на новых длинах волн возможна с использованием эффекта вынужденного комбинационного рассеяния (ВКР). Не так давно было продемонстрировано успешное объединение этих подходов - генерация СЧДС на новых длинах волн посредством ВКР как внутри резонатора импульсного волоконного лазера [1], так и во внешнем кольцевом резонаторе с синхронной накачкой импульсным лазером [2]. Для увеличения сдвига длины волны, который в данных работах составил 13 ТГц, можно использовать другие типы волокон, например, фосфосиликатные $\left(\mathrm{P}_{2} \mathrm{O}_{5}\right)$, где этот сдвиг составляет величину 39 ТГц. При накачке в области 1,1 мкм такое волокно позволяет получить генерацию как раз на длине волны 1,3 мкм.

Для указанного диапазона до недавнего времени полностью отсутствовали активные среды, позволяющие получить непосредственно лазерную генерацию. Стандартным методом получения импульсов в районе 1,3 мкм является рамановский самосдвиг частоты при распространении в волокне импульсов, генерируемых в более коротковолновой области $[3,4]$. Однако для этого метода необходимо обеспечить аномальную дисперсию волокна, что в данном спектральном диапазоне достигается только использованием специальных волокон, поддерживающих моды высоких порядков [4]. Всё это делает метод рамановского самосдвига крайне сложным и дорогостоящим в реализации. Недавно также была получена прямая генерация пикосекундных импульсов при использовании фосфосиликатных волокон, легированных висмутом [5]. Однако энергия импульсов в этом случае не превышала 9 нДж даже после их усиления.

В данной работе мы исследуем возможность генерации СЧДС в области 1,3 мкм во внешнем фосфосиликатном резонаторе. Схема исследуемого лазера состоит из волоконного лазера накачки и внешнего волоконного кольцевого рамановского резонатора. Так как генерация сильночирпованных диссипативных солитонов возможна только в области нормальной дисперсии, значения этого параметра были предварительно измерены для ряда доступных волокон. Для используемого фосфосиликатного волокна она оказалась нормальной и составила

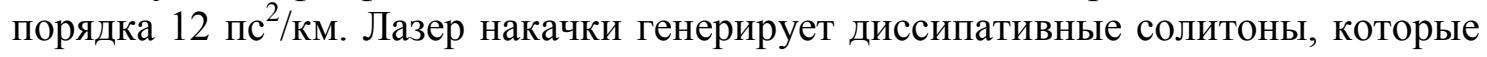
после предварительного растяжения и усиления заводятся во внешний резонатор. Длина внешнего кольца выбрана так, чтобы частота повторения накачки была кратна четвёртой части частоты прохождения солитонов по кольцу. Т. е. внешний 
резонатор в четыре раза длине резонатора задающего генератора, что позволяет увеличить длину взаимодействия генерируемого излучения и накачки в фосфосиликатном волокне.
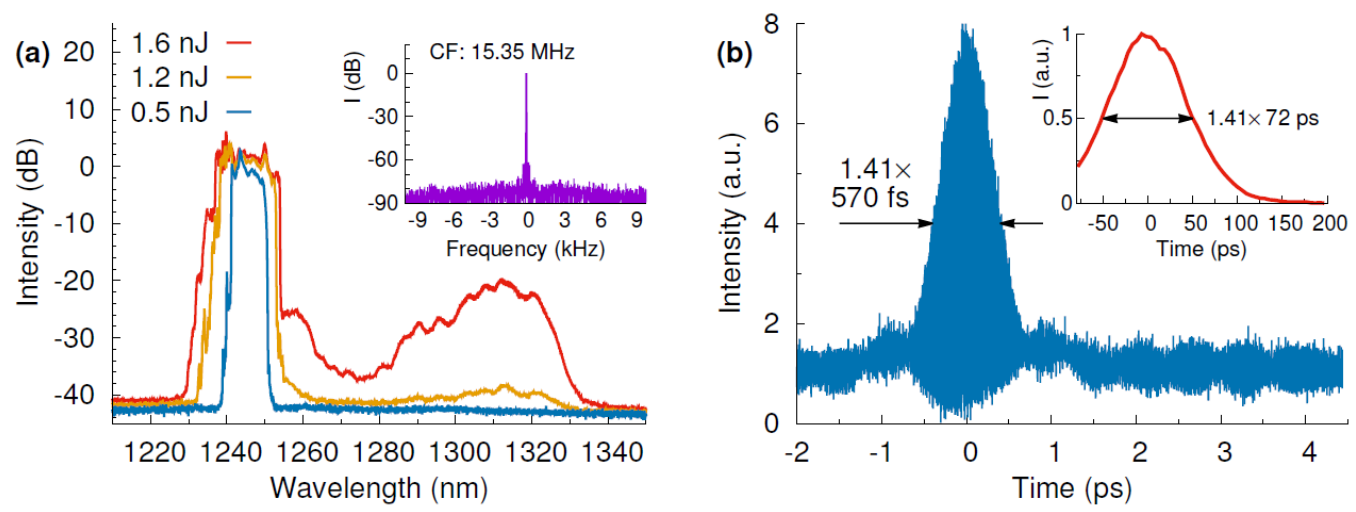

Рис. 1. Характеристики итоговых импульсов: (а) оптический и радио-частотный (внутри) спектры, (b) автокорреляционные функции до (внутри) и после сжатия.

В ходе работы была произведена оптимизация параметров лазера накачки, таких как энергия и длительность импульсов. Частота повторения составляла 15,35 МГц. Так же исследовалась генерация итоговых импульсов при различных коэффициентах выходного ответвителя. Оптимальным оказался коэффициент вывода 20\%. Энергия импульсов на выходе достигла 1,6 нДж, ширина спектра превышала 10 нм, а центральная длина волны генерации составила 1245 нм. Прямоугольная форма спектра и форма автокорреляционной функции соответствовали случаю генерации СЧДС [6]. Сжатие производилось при помощи компрессора на дифракционных решётках. В результате длительность импульсов уменьшилась с 72 пс до 570 фс [7].

Таким образом, в ходе работы была получена генерация импульсов на длине волны 1245 нм с энергией 1,6 нДж, частотой повторения 15,35 МГц и шириной спектра больше 10 нм. Длительность импульсов после сжатия составила 570 фс. В результате дальнейшей оптимизации и усиления данный источник может быть интересен для применений в биологии, в первую очередь, для многофотонной микроскопии.

Работа выполнена при финансовой поддержке РФФИ (№ 18-32-00409), работа С.А.Бабина поддержана Комплексной программой фундаментальных научных исследований СО РАН «Междисциплинарные интеграционные исследования», проект №38 (0319-2017-0011).

\section{Литература:}

[1] D. S. Kharenko et al, Opt. Lett., 37, 4104-4106 (2012)

[2] D. Churin et al, Opt. Lett., 40, 2529-2532 (2015)

[3] Xu, C., and Wise, F. W., Nat. Photonics 7, 875-882 (2013)

[4] L. Rishoj, G. et al, Conf. Lasers Electro-Optics, STh3O.3 (2016)

[5] A. M. Khegai et al, Quantum Electron., 46, 1077-1081 (2016)

[6] S. Smirnov et al, Opt Express, 20, 27447 (2012)

[7] D. S. Kharenko et al, Opt Express, 26, 15084 (2018) 